\title{
O ENSINO DO DIREITO NA EDUCAÇÃO INFANTIL: UMA ANÁLISE DA LEI ORDINÁRIA No 8340/2018 DE MARÍLIA/SP
}

\author{
Francisco Morilhe Leonardo ${ }^{1}$
}

\begin{abstract}
Resumo: $\mathrm{O}$ presente artigo tem por objetivo analisar a lei ordinária no 8340/2018 do município de Marília-SP que autoriza o Executivo dispor acerca da introdução de noçóes de Direito Constitucional, Justiça e Cidadania no currículo escolar da rede municipal de ensino, na qual destina aos estudantes da Educação Infantil ao Ensino Fundamental, demonstrando a importância da referida lei para os estudantes e a sociedade, uma vez que, há somente projetos no país, nessa seara. A inclusão pode-se dar de forma lúdica e pedagógica aos discentes e se considera que a escola deve contribuir com a preparação do exercício futuro da cidadania, cujo propósito é fundamental aos cidadãos que atuarão na construção de um Estado democrático em prol dos Direitos Humanos, mesmo em tenra idade. Para tanto, objetiva-se discutir a Educação Infantil no contexto das políticas educacionais no Brasil, na qual a referida lei é pioneira nesse sentido, além da importância de sua efetivação, o que se permite concluir que a inclusão jurídica poderia ocorrer em outras escolas, de outras cidades do país, uma vez que a lei obteve êxito educacional na referida cidade e serve como modelo para as demais. Assim, será destacado, inicialmente, o nível de ensino no cenário político nacional, enfatizando a importância das inovaçôes curriculares de modo que se inclua a Educação Jurídica e, num segundo momento, o Direito à Educaçáo, associado aos Direitos Humanos, em que se finaliza com a proposta pedagógica apresentada.
\end{abstract}

Palavras-chave: Educação Infantil; Cidadania; Ensino Jurídico; Direitos Humanos.

\section{TEACHING LAW IN CHILDHOOD EDUCATION: AN ANALYSIS OF ORDINARY LAW N 8340/2018 OF MARÍLIA / SP}

\begin{abstract}
The purpose of this article is to analyze Ordinary Law No. 8340/2018 of the municipality of Marília-SP that authorizes the Executive to provide for the introduction of notions of Constitutional Law, Justice and Citizenship in the school curriculum of the municipal school system, in which it is intended for students from kindergarten to elementary school, demonstrating the importance of this law for students and society, since there are only projects in the country in this area. Inclusion can be given in a playful and pedagogical way to students and it is considered that the school should
\end{abstract}

1 Mestre em Didática do Ensino do Direito pelo UNIVEM - Centro Universitário Eurípedes de Marília-SP. 
contribute to the preparation of the future exercise of citizenship, whose purpose is fundamental to the citizens who will act in the construction of a democratic State in favor of Human Rights, even at a young age. Therefore, the objective is to discuss Early Childhood Education in the context of educational policies in Brazil, in which the referred law is a pioneer in this sense, in addition to the importance of its implementation, which allows us to conclude that legal inclusion could occur in other schools, from other cities in the country, since the law was educationally successful in that city and serves as a model for the others. Thus, initially, the level of education in the national political scenario will be highlighted, emphasizing the importance of curricular innovations in a way that includes Legal Education and, in a second moment, the Right to Education, associated with Human Rights, in which it ends with the presented pedagogical proposal.

Keywords: Child Education; Citizenship; Legal Teaching; Human rights.

\section{INTRODUÇÃO}

O direito à Educação, a política de Educação Infantil e as práticas curriculares com as crianças merecem um caráter passível de reflexão, pois geram discussóes educacionais e ação de movimentos sociais no país a fim de se buscar, sempre, melhores condiçôes e eficiência desse direito. O direito à educação é um dos direitos sociais e envolve a cidadania, se destacando no bojo da sociedade por ser fundamental e, desse modo, ao Estado, assiste-lhe o dever de sua garantia, sendo obrigatório constitucionalmente.

A Constituição Cidadã de 1988 e o Estatuto da Criança e do Adolescente reconheceram tal direito que também fora corroborado em 1996 pela Lei de Diretrizes e Bases da Educaçáo, cujo teor é contido da mesma maneira nas Diretrizes Curriculares para a Educação Infantil e no Plano Nacional de Educação, recentemente, em 2010 e 2014, respectivamente. Dessa forma, geraram-se consequências para as políticas municipais e estaduais educacionais, cujo foco visa a busca de opçóes para que a prática desse direito social, mais do que afirmado, seja uma realidade para os alunos.

Assim, a conexão às noçôes do Direito por meio de atividades curriculares compreende a importância da proposta que se defende sob o âmbito jurídico e social. Tal caminho, por certo, permite ao aluno melhor compreensão e entendimento acerca dos direitos fundamentais e o civismo, de acordo com sua faixa etária, previstos na Constituição Federal de 1988, o que possibilitará maior luta pelos direitos e sua cidadania, na perspectiva da efetivação da justiça.

O civismo corresponde a um "Sistema de governo em que predominam os civis" (BUENO, 2017, p. 170). Aqui o termo "sistema de governo" pode-se destacar, como exemplo, o presidencialismo e parlamentarismo. Ademais, conceitua-se civismo como a "devoção pelo interesse público; patriotismo" (BUENO, 2017, p. 170). Desse modo, percebe-se que os termos têm origem da palavra "cidadania", que vem do latim civitas, significando "conjunto de direitos atribuídos ao cidadão" ou "a cidade" (FISCHER, 2018). Assim, vê-se uma semelhança, unindo a palavra "civismo" ao termo "cidadania", fundamentalmente no que se refere à formação de uma noção para definição. 
Nesse contexto, ter acesso ao conteúdo básico jurídico, mesmo que numa tenra idade, é de vital importância para os cidadãos, pois ninguém pode alegar o desconhecimento da lei ou do próprio direito, quando uma norma é legalmente positivada no ordenamento jurídico e de conhecimento geral. Além disso, desperta desde cedo a questão do exercício para a cidadania, auxiliando na construção dos valores a esses cidadáos.

De igual sorte, objetiva-se com a presente pesquisa analisar a referida lei municipal, de modo a ressaltar que o acesso às noçóes jurídicas, no campo da Educação Infantil e da família, tem suma importância para os estudantes. Assim, reflete-se acerca da eficiência da cidadania objetivando a garantia dos direitos e deveres fundamentais da Lei Maior de 1988, pois em longo prazo será possível atingir uma melhor formação jurídica, cultural e cidadã, além do mais, por meio da Lei Ordinária no 8340/2018, do município de Marília-SP, que autoriza o Executivo dispor acerca da introdução de noçôes de Direito Constitucional, Justiça e Cidadania no currículo escolar municipal, na qual destina aos estudantes da Educação Infantil e aos primeiros anos do Ensino Fundamental, possibilitando introduzir noçóes do Direito, de uma forma pedagógica, variando com a idade dos discentes.

Nesse diapasão, a pesquisa enfoca a problematização por ser imprescindível incluir o estudo de noções do Direito na Educaçáo Infantil, pois, vislumbra-se tal relevância desse ensinamento aos alunos de modo a garantir o acesso básico à educação jurídica e à justiça, dada a importância do futuro cidadão na democracia. Sendo assim, justifica-se, para tanto, demonstrar que inclusão extracurricular desses conteúdos, na Educação Infantil, pode gerar resultados positivos em longo prazo.

A presente pesquisa descreverá um relato de experiência feito na cidade de Marília/SP, com alunos de uma escola de Educação Infantil e terá a abordagem qualitativa, revisão bibliográfica, além do método dedutivo. Assim, abordase a educação como garantia constitucional, expondo a proposta de inclusão da Educação Jurídica em atividades próprias, devendo ressaltar o acesso à justiça e à Educaçáo Jurídica, como uma proposta pioneira, além da importância da sua efetividade. Destarte, serão descritos os conteúdos jurídicos que poderão ser levados ao público escolar infantil, bem como os resultados colhidos e os apontamentos conclusivos.

Em suma, num período em que a cidadania passa por novos desafios, procuram-se novos meios de atuação de modo a eleger novas áreas por intermédio das grandes transformaçóes atuais. É importante destacar que, ter o conhecimento dos direitos básicos que do cercam o cotidiano das pessoas, como regras de convivência, leis que regem à ordem ambiental, civil, de trânsito, entre outras, significa obter caminhos rumo ao progresso visando à garantia de um futuro melhor para as crianças. 


\section{A EDUCAÇÁO INFANTIL E O ENSINO JURÍDICO NO CENÁRIO NACIONAL}

Hodiernamente, o direito das crianças cursarem a Educação Infantil remete-se à promulgação da Carta Magna de 1988, do Estatuto da Criança e do Adolescente de 1990 e da Lei de Diretrizes e Bases da Educação Nacional (no 9.394/1996), haja vista que, foi a partir das deliberaçóes encaminhadas nessas leis e das suas consequências para a área educacional que os obstáculos e as perspectivas têm sido elencados e buscam-se soluçóes a fim de minimizá-los, razão em que o conhecimento básico jurídico pode ser um caminho benéfico em prol da cidadania.

No Brasil, as lutas em torno da Constituinte de 1988, do Estatuto da Criança e do Adolescente e da Lei de Diretrizes e Bases da Educação Nacional, e as discussōes em torno da atuação do Ministério da Educação nos anos de 1990 são parte de uma história coletiva de intelectuais, militantes e movimentos sociais. Influenciados por orientaçôes de agências internacionais e por programas desenvolvidos no exterior, documentos oficiais do MEC e pareceres do então Conselho Federal de Educação defendiam a ideia de que a pré-escola poderia, por antecipaçáo, salvar a escola dos problemas relativos ao fracasso escolar (KRAMER, 2006).

A Educação Infantil compõe a Educação Básica, definida no texto da Lei de Diretrizes e Bases da Educação Nacional é dada como um direito e se conceitua de modo a esclarecer e gerir um conjunto de inovaçóes trazidas pela busca de um espaço público inovador em que se pode democratizar o Direito, que poderá ser trabalhado e estudado desde a pré-escola. Saviani $(1997$, p. 190) relata que "a Educação Básica deve ser analisada tanto do ponto de vista dos objetivos proclamados quanto dos objetivos reais, uma vez que os primeiros indicam as finalidades gerais e amplas e, os segundos, os alvos concretos das açóes". O autor completa:

Enquanto os objetivos proclamados se situam num plano ideal onde o consenso e a convergência de interesses é sempre possível, os objetivos reais situam-se num plano onde se defrontam interesses divergentes e por vezes antagônicos, determinando o curso da ação às forças que controlam o processo (SAVIANI, 1997, p. 190).

Por via de consequência, cumpre ressaltar que a Lei de Diretrizes e Bases da Educação, de 1996, foi calcada na Constituição Federal de 1988, reconhecendo como direito do menor o acesso à Educação, sejam nas creches ou pré-escolas, até os cinco anos de idade, sendo tal competência do Estado o cumprimento desse direito social. Ademais, a lei visou discussóes de modo que se avançassem na seara educacional, objetivando um trabalho com um fim educativo-pedagógico moldado às especificidades para as crianças. Chauí (1989) nos ensina que:

A prática de declarar direitos significa, em primeiro lugar, que não é um fato óbvio para todos os homens que eles são portadores de direitos e, por outro lado, significa que não é um fato óbvio que tais direitos devam ser reconhecidos por todos. A declaraçáo de direitos inscreve os direitos no social e no político, afirma sua origem social e política e se apresenta como objeto 
que pede o reconhecimento de todos, exigindo o consentimento social e político (CHAUÍ, 1989, p. 20).

Por via de consequência, a Educação Básica é fundada ao bem público, implicando a cidadania no seu exercício consciente por qualificar os discentes para o mundo do trabalho, conforme preconiza o texto constitucional, sendo dever do Estado, assumindo, antes de tudo, uma perspectiva histórica, crítica, de inserção e protagonismo diante da realidade. Trata-se de um direito juridicamente protegido, classificado, constitucionalmente, como direito social e, corroborando com a autora, sua origem deve se apresentar como um fator que pede o reconhecimento de todos, cuja modalidade de ensino deve ser ofertada, garantindo todas as condiçóes ao seu acesso em prol do educando.

Assim, devido tal incumbência por parte do Estado, nascem as obrigaçôes que devem ser respeitadas, tanto da parte de quem tem a responsabilidade de efetiválas, como os poderes constituídos, quanto da colaboração vinda da parte de outros sujeitos implicados nessas obrigaçôes (CURY, 2002).

A questão sobre a introdução jurídica tem grande significado, pois auxilia na visão das crianças como criadoras de cultura. Há a concretização de tendências para a Educação Infantil que visam valorizar o saber que os infantes trazem do seu meio sociocultural de origem e que pode gerar um avanço no campo teórico e também na seara dos movimentos sociais e das lutas a fim de mudar a situação da educação das crianças.

Nesse panorama, o cenário político apresenta, para os professores, um importante desafio para a atuação das políticas educacionais. Nesse viés, o professor é um elemento integrador entre a aprendizagem e o ensino, pois o conjunto de fatos objetiva ao equilíbrio e a orientação da intervenção pedagógica para que a criança aprenda da melhor forma, ou seja, lúdica e pedagógica, o conjunto de açóes que envolvam a cidadania, a justiça e a Constituição.

Destarte, Freire (2003, p. 160) afirma que “a mera transmissão do conhecimento pelo professor e a sua reprodução pelo aluno é uma das formas de confirmação da dominação vigente". O autor ratifica que o conhecimento não é algo dado e acabado, mas um processo social que demanda a ação transformadora dos seres humanos sobre o mundo.

Nesse ínterim, o elemento de reflexão contínua corrobora na atuação do docente no ensino da noção jurídico-educativa, cujo instrumento possibilita a criança ter consciência de seus avanços sociais, dificuldades e possibilidades, ação que envolve todo o processo de ensino e aprendizagem das etapas traçadas.

Para Pôrto (2000), a estratégia de transformação curricular pode ser obtida pela ocupação das "brechas" do projeto pedagógico, como alternativas de paulatina modificação e introdução ao Ensino Jurídico. Isso demonstra que é necessária a construção de novas propostas capazes de modificar o modelo existente. Dessa feita, surge um "risco do aprendizado" a ser buscado. 
Nesse diapasão, tal introdução origina-se, também, à humanização, ou seja, pode gerar uma possibilidade de que, mesmo sob a supremacia liberal e do âmbito do Ensino Jurídico em constante desenvolvimento, é possível gerar dispositivos estratégicos em seu interior objetivando revirar a práxis didática e a transformála numa ação efetiva de emancipação social. Kramer (2003) assinala que a préescola precisa ser pensadas como instâncias de formaçáo cultural e as crianças, como sujeitos de cultura e história, como sujeitos sociais.

Assim, conceber a escola da infância como instituição provedora da humanização da criança requer conhecer os períodos do desenvolvimento psíquico individual de cada faixa etária. Portanto, o docente terá um aporte teórico acerca para desenvolver um trabalho pedagógico intencional e de qualidade, propiciando o desenvolvimento da atividade principal em cada período. É por meio das atividades principais que a criança se relaciona com o mundo e, em cada estágio, de modo a gerar necessidades específicas em termos psíquicos (FACCI, 2004). Sobre a questáo da humanização na Educação Infantil, Vicentini e Barros (2017) contribuem, ao afirmarem que:

[...] Cabe à escola infantil, enquanto o lugar mais importante para o desenvolvimento das crianças, desempenhar a função humanizadora, planejando um trabalho intencional, estabelecendo relaçóes saudáveis entre as próprias crianças e os adultos, e possibilitando o acesso à cultura. Para que escola concretize seu papel humanizador, é imprescindível apostar em cursos de formaçáo continuada para os professores, que ofereçam momentos de estudo e reflexão sobre sua práxis pedagógica, a fim de provocar mudanças no trabalho docente possibilitando a aprendizagem e o desenvolvimento das crianças pequenas (VICENTINI; BARROS, 2017, p. 42-43).

Dessa forma, torna-se possível proporcionar reflexóes sobre a importância da educação, como "indispensável para repassar o conhecimento jurídico para a sociedade por meio das escolas, o direito que o homem tem de educar-se, de desenvolver-se intelectualmente, como, também, aponta a obrigação do Estado para com a Educação" (LEONARDO, 2015, p. 667).

Em resumo, é imperioso salientar que a Carta Magna de 1988 remodelou os princípios da República e, nesse viés, esse novo modelo político pôs a criança num contexto de cidadania e definiu novas relaçóes entre ela e o Governo. Os principais dispositivos constitucionais que criaram o novo paradigma para essa relação testificam os direitos do infante "[...] a salvo de toda forma de negligência, discriminação, exploração, violência, crueldade e opressão" (BRASIL, 1988), além de ser um sujeito de direitos que são garantidos com absoluta prioridade pela família, pela sociedade e pelo Estado, além da tutela constitucional ao direito à Educação.

\section{A EDUCAÇÁO INFANTIL COMO DIREITO E SUA EFETIVIDADE E OS DIREITOS HUMANOS}

De início, é imperioso destacar que, o direito à educação, conquanto direito humano e fundamental, tem sido contextualizado, ao decorrer dos tempos por 
meio de documentos, movimentos e campanhas de afirmaçáo e legitimação dos direitos da pessoa humana e esteve estreitamente relacionado ao próprio progresso dos direitos humanos.

É relevante ressaltar, nesse sentido, de acordo com Benevides (2003), a Educação em Direitos Humanos parte de três pontos, sendo que, primeiramente, trata-se de uma educaçáo permanente, continuada e global. Ademais, está voltada para a mudança cultural e, por fim, é educação em valores, para atingir coraçóes e mentes e não apenas instrução, ou seja, não se trata de mera transmissão de conhecimentos.

Nesse viés, a Declaraçáo de Viena destacou a relevância da educação em Direitos Humanos a ser efetivada, considerando-a como elemento primordial de promoção de vínculos harmoniosos nas sociedades, hábil a suscitar ao respeito mútuo, a tolerância e a paz, reiterada pela exposiçấo dos teores e processos pelos quais a tarefa de educar em direitos humanos pode ser concretizada.

A educação em direitos humanos deve incluir a paz, a democracia, o desenvolvimento e a justiça social, tal como previsto nos instrumentos internacionais e regionais de direitos humanos, para que seja possível conscientizar todas as pessoas em relaçáo à necessidade de fortalecer a aplicação universal dos direitos humanos (DECLARAÇÃO E PROGRAMA DE AÇÃO DA CONFERÊNCIA MUNDIAL SOBRE OS DIREITOS HUMANOS, 1993).

De modo a estabelecer uniōes imprescindíveis ao entendimento entre o direito à Educação e aos Direitos Humanos que se torna um fator fundamental, de modo que, aliado ao contexto de afirmação, a tutela educacional se dá devido sua efetivação. Ademais, as discussões sobre os Direitos Humanos conduzem à conclusão de que, para a vigência de uma sociedade mais livre, justa e solidária, em conformidade com os fundamentos da Carta Magna, denota-se uma ação mais eficiente a ser entabulada.

Atualmente, a educação voltada aos Direitos Humanos conduz certas ações nas quais os alunos devem conhecer principalmente o básico em relação aos seus direitos e deveres, o que poderia ser ofertado pelo Estado desde a etapa pré-escolar. Nesse sentido, o Plano Nacional de Educação em Direitos Humanos (PNEDH), lançado no ano de 2003, demonstra a preocupação do Estado brasileiro em relação à construção de uma sociedade justa, equitativa e democrática, fundamentada na educação em direitos humanos e cidadania, a qual é indicada de acordo com os seguintes critérios para a Educação Básica (BRASIL, 2003).

Assim, é exposto no referido documento:

A educação em direitos humanos deve estruturar-se na diversidade cultural e ambiental, garantindo a cidadania, o acesso ao ensino, permanência e conclusão, a equidade (étnico-racial, religiosa, cultural, territorial, físico individual, geracional, de gênero, de orientação sexual, de opção política, de nacionalidade, dentre outras) e a qualidade da educaçáo (BRASIL, 2003, p. 24). 
Aliás, sobre a Educaçáo Infantil, destaca-se que a creche, que abriga, durante o dia, alunos de pouca idade, ou seja, até os três anos, adquiriu um novo tratamento com a Carta Magna de 1988 em que está inserta no capítulo que versa sobre Educação, testificando o zelo envolvido e a atençáo às crianças mais novas.

Os direitos da criança (e do adolescente) devem ser atendidos pela família, pela sociedade e pelo Estado com absoluta prioridade, segundo o artigo $227 \mathrm{da}$ $\mathrm{CF} / 88$. O Estado tem o dever de garantir a educaçáo infantil às crianças de até cinco anos em creches e pré-escolas, disposto no artigo 208, IV da CF/88. A Emenda Constitucional no 53/ 2006 baixou de seis para cinco anos o período da Educação Infantil porque, em 2005, o início do Ensino Fundamental obrigatório foi estabelecido aos seis anos (BRASIL, 1988).

Assim, a referida Lei Maior consagra a competência dos municípios de modo a cooperarem com a União e o Estado, autorizando a estes e elaboração de programas para a Educação Infantil e ao Ensino Fundamental. Nesse sentido, no que tange à educação, os municípios devem contribuir, prioritariamente, com a Educação Infantil e o Ensino Fundamental.

Nessa esteira, o Estatuto da Criança e do Adolescente consagra um novo prisma destes na sociedade hodierna, desviando o foco autoritário, paternalista, assistencialista e repressivo, de modo a enfatizar o ponto mais importante que é o da criança cidadá, aquela sujeita de direitos, em fase de desenvolvimento e formação. Ademais, emprega a doutrina da tutela integral, em que, nesse diapasão, se destacam três itens:

a) a descentralização político-administrativa da atenção aos direitos da criança - à União cabe formular a política nacional e as diretrizes gerais; aos municípios, bem como ao Distrito Federal, o atendimento, contando, para isso, com a cooperação técnica e financeira da União e do estado;

b) a participação da sociedade, por meio de suas organizaçóes representativas, na formulação das políticas, no planejamento das açóes e no controle da açáo do Estado, em todos os níveis;

c) a criaçáo do Sistema de Garantia de Direitos da criança e do adolescente, que começa a contribuir para que as crianças tenham acesso à creche e à préescola e nela recebam educação integral de qualidade. O Conselho Tutelar, os Conselhos Nacional, Estaduais e Municipais dos Direitos da Criança e do Adolescente, o Ministério Público e outras organizaçóes da sociedade são chamados a zelar por que os direitos da criança sejam atendidos, entre eles, o direito à educação a partir do nascimento (NUNES, et al., 2011, p. 33).

A LDB define a educação infantil como primeira etapa da educação básica e atribui a ela "como finalidade o desenvolvimento integral da criança até cinco anos de idade, em seus aspectos físico, psicológico, intelectual e social, complementando a ação da família e da comunidade", conforme artigo 29 da LDB (BRASIL, 1996). A creche, entretanto, tem a funçáo de iniciar essa educação integral, da mesma maneira que a pré-escola, de dar continuidade.

Oriani (2008) afirma que a educação é conceituada como "o ato de desenvolver as faculdades, psíquicas, intelectuais e morais", além de ser um direito fundamental 
também é o meio pelo qual se conquista outros direitos. A necessária formação para os profissionais da educação se dá em nível superior, ou seja, num curso de licenciatura em unidades de Ensino Superior. Outrossim, a resoluçáo do Conselho Nacional de Educação (CNE) retira a habilitação exclusiva para a Educação Infantil, bem como outras habilitaçóes, ao curso de Pedagogia, aumentando-se, assim, a área de atuação do docente.

Mesmo assim, exige que o curso ofereça estudos e prática de ensino também em Educação Infantil, de sorte que o estudante seja formado para, entre outras atividades educacionais, "compreender, cuidar e educar crianças de zero a cinco anos, de forma a contribuir para o seu desenvolvimento nas dimensóes, entre outras, física, psicológica, intelectual e social” (BRASIL, 2006).

Ademais, cabe salientar que, no artigo 62 da LDB, "é admitida, na Educação Infantil e nas quatro primeiras séries do Ensino Fundamental, a formação mínima de magistério de nível médio, na modalidade normal" (BRASIL, 1996). A referida lei marca, assim, a profissionalização da Educação Infantil, ou seja, somente serão admitidos professores habilitados em nível superior ou formados por treinamento em serviço.

Contudo, a partir de 2006, certos concursos públicos tinham como requisito de admissão a formação específica no nível de graduação, entretanto, após tal época, muitas redes admitiram a volta do magistério. Desse modo, a rede privada a mercê de suas próprias escolhas, ou seja, algumas redes, a partir da LDB, de 1996, aceitaram professores com graduação específica, mas, outras, no entanto, admitiram ainda o Magistério (VENTURINI, 2019). E é sobre esse ponto de formação profissional que Nunes et al. (2011) destacam a questão da profissionalização da Educação Infantil e das séries iniciais no país que, antes da promulgação da referida lei, a formação não compunha a agenda educacional.

Além disso, a Lei de Diretrizes e Bases da Educação Nacional de 1996, em seu artigo 89, determina que as creches sejam integradas aos respectivos sistemas de ensino, estabelecendo um prazo de três anos para efetivar essa passagem (BRASIL, 1996). Em síntese, a legislação educacional brasileira, a partir de 1996, expóe com clareza a concepçáo de educação desde o nascimento, em estabelecimentos educacionais, com finalidade de desenvolvimento integral.

Vale lembrar que, o tratamento constitucional do direito à educação está particularmente ligado à busca do ideal de isonomia que qualifica os direitos fundamentais. Por sua vez, os direitos sociais se enquadram num viés de igualdade material que se dá por meio da ação estatal voltada à garantia de padróes mínimos para a Educação, para quem não conseguiu ter acesso por meios próprios. Assim, urge a oferta de condiçôes básicas para que o indivíduo possa, efetivamente, se valer das liberdades que o Poder Público lhe outorga.

Em se tratando de efetividade de uma lei, tal fato se revela em razão da norma jurídica se impor perante quem quer que seja. Em outras palavras, uma norma jurídica será efetiva se observada tanto pelos aplicadores do Direito como pelos destinatários dessas normas, ou seja, a partir do momento em que foi sancionada, 
todos os cidadãos brasileiros estamos sujeitos à sua imposição (OLIVEIRA; SILVA, 2017).

Além disso, a eficácia, por sua vez, testifica que a norma cumpriu a finalidade a qual se destinava, pois foi socialmente observada e realizada, tendo solucionado o motivo que a gerou. Assim, "uma lei é eficaz quando cumpre a sua função social, quando regula injustiças, crimes, convençôes que comprometem relaçốes éticas" (OLIVEIRA; SILVA, 2017, p. 02).

A lei em questáo fortalece mecanismos para que o Poder Público possa autorizar a inserção de conteúdos jurídicos aos níveis de ensino a qual lhe compete o Município. O tema em questáo possui relevância singular por se inserir numa das searas mais frequentes da sociedade, que é a importância da Educação, especialmente em tempos de tantas degradaçôes desse direito social, haja vista que tal introdução pode contribuir com a questão da cidadania.

\section{A PROPOSTA PEDAGÓGICA DO ENSINO JURÍDICO NA EDUCAÇÃO INFANTIL DA LEI ORDINÁRIA No 8340/2018 DO MUNICÍPIO DE MARÍLIA/SP}

A Educação Infantil enfrenta, atualmente, entraves em vários âmbitos de sua composição estrutural, seja política, econômica e social, traduzindo em críticas em sua conjuntura. Desse modo, observa-se que, no dia a dia da rotina escolar é possível a tentativa dos professores da Educação Infantil iniciarem a formação cidadã dos infantes se houver apoio gerencial.

A inclusão de noçôes jurídicas desde a pré-escola contribui com o estudo básico do Direito para o público infantil, como ciência, pois não seria exclusividade somente aos que tem acesso ao curso específico. Entretanto, "a democracia real, em que todos têm igualdade de oportunidades de tratamento, somente a possível com a descentralização em que todos são ouvidos em uma ideia, uma solução, é boa, venha de quem e de onde vier" (ROLDAN, 2016, p. 45).

Assim, cabe destacar que, as observaçóes do cotidiano escolar foram realizadas em uma escola municipal de Educação Infantil da cidade de Marília/SP, sendo que a referida escola é orientada pelos documentos e leis, sejam estes: a Lei de Diretrizes e Bases da Educação Nacional no. 9.394/96, os Referenciais Curriculares Nacionais para a Educação Infantil e as Diretrizes Curriculares Nacionais para a Educação Infantil. Nesse sentido, pela democratização do Direito, Leonardo (2016) aduz que:

A democratização do conhecimento jurídico básico, por certo, admite ao educando uma compreensão e um melhor entendimento acerca dos direitos fundamentais elencados na Constituição Federal de 1988, o que permitirá uma maior busca pelos direitos, na ótica da efetivação da justiça. Nesta perspectiva, o ensino jurídico aos infantes é de vital importância, pois a ninguém é permitido alegar desconhecimento da lei ou do próprio direito, já que, quando uma lei é legalmente positivada no ordenamento jurídico, é, de fato, do conhecimento coletivo, uma vez que foi publicada e atinge crianças e adultos (LEONARDO, 2016, p. 354). 
Ademais, destaca-se o relato de caso, como exemplo, realizado numa escola de Educação Infantil pelo autor e uma professora da rede, do município de Marília/ SP, em que se observou que, na turma de Infantil II, cujas idades dos alunos variam entre cinco a seis anos, a possibilidade em se trabalhar esse ideal, pois se construiu junto ao educando, algumas questóes cujos temas envolvem os Direitos Humanos e Cidadania, o que fora observado de alguma maneira nas atividades, visualizando a aceitação dos alunos, em que se foi ratificado devido algumas atitudes e diálogos deles, entre si.

Nesse panorama, vislumbra-se, de igual modo, que durante as rotinas e as atividades foi possível analisar os temas relacionados aos Direitos Humanos e a formação de cidadáos, apesar de serem importantes para toda sociedade e serem amparados por leis e documentos, independentemente da idade, pois demonstram que as preocupaçóes dos envolvidos na rotina escolar não deveriam somente se limitar ao ato de cuidar, e sim, ao ato de educar para cidadania, desde a tenra idade, pois este ideal deve permanecer adido às práticas pedagógicas.

Por outro prisma, observou-se que, mesmo numa fase pré-escolar, o aluno tem potencialidade de ser capaz em compreender parcialmente os direitos relativos ao Homem, de forma sucinta, fato este que não justifica a ausência da abordagem às temáticas inerentes aos Direitos Humanos e Cidadania nesse nível de ensino. Igualmente, constatou que a própria comunidade aprovou a iniciativa, pois de alguma forma foram envolvidos com o conhecimento jurídico básico.

Infere-se, de igual sorte que, o desconhecimento dos direitos básicos por parte da sociedade reduz devido a oferta da inclusão jurídica, a começar pela Educação Infantil, imprescindível às práticas pedagógicas nas escolas. Portanto, os resultados obtidos no trabalho realizado na escola infantil foram satisfatórios e importantes para a vida dos futuros cidadãos, como qualquer outra disciplina, como Matemática e Língua Portuguesa. Ainda, Leonardo (2016) assevera que:

Evidencia-se a relevância da inclusão jurídica a ser estudada nas escolas de Educação Infantil e Fundamental, cujo escopo é contribuir para a formação da cidadania e o preparo para a vida em sociedade, auxiliando numa melhor formação escolar. Ademais, em longo prazo, terão uma formação cultural jurídica de suma importância para o crescimento do país. Por derradeiro, vislumbra-se a relevância do referido projeto de lei municipal e que este seja objeto de apreciação aos legisladores de outras esferas, de modo a democratizar o Direito e ao exercício da cidadania (LEONARDO, 2016, p. 356).

Seguindo essa linha de raciocínio, baseado na lei ordinária no 8340/2018, do município de Marília/SP, a fim de compartilhar os conhecimentos vinculados à cidadania, foram formuladas atividades lúdicas e pedagógicas englobando o estudo do Direito visando à democracia jurídica de modo a beneficiar a construção dos valores do infante visando seu exercício pleno de direitos.

Assim, a citada lei tem a seguinte diretriz: Noçóes básicas de Justiça e Cidadania e Noçóes básicas sobre a Constituição Federal de 1988 destinado à Educação Infantil e Fundamental. Na justificativa, segundo Leonardo (2016), foi 
relatado que a lei visa, essencialmente, proporcionar reflexóes de forma que nossos alunos possam participar mais destacadamente da realidade de sua comunidade, despertando e criando interesse pelas decisóes que, direta e indiretamente, o afetam e desenvolvendo uma consciência cívica voltada às necessidades públicas. Propóe-se, de modo diferenciado, ou seja, de acordo com a faixa etária dos alunos, de forma lúdica e pedagógica, discussôes sobre a introdução do que é o Direito, sendo com certeza, imprescindível para a formação dos cidadáos que atuarão na construção de um Estado democrático, tendo em vista a garantia dos valores e princípios necessários à formação e exercício da cidadania pelos alunos.

Nesse sentido, o trabalho se deu, inicialmente, na realização de uma apresentação do tema para as crianças e para a família a fim de que todos acompanhassem o desenvolvimento e a proposta da lei para a inclusão de noçóes jurídicas na Educação Infantil, seguindo a interdisciplinaridade com os eixos temáticos. Assim, foi realizada a leitura da Declaração Universal dos Direitos Humanos para as crianças, além de assuntos que surgiram diariamente que estavam insertos na proposta do projeto.

Com a anuência dos pais e responsáveis, além da equipe gestora, com a devida autorização, foram realizadas as atividades durante o período letivo, em 2015 e 2016. Durante esse período foram feitas, aproximadamente, vinte atividades com os mais variados temas que envolvem o Direito, cujas tarefas eram registradas em Diário de Classe e Semanário, apresentado à Coordenaçáo Escolar, obtendo sua concordância.

Portanto, em seus cinco artigos, a referida lei municipal preconiza, inicialmente, que o Executivo está autorizado a adotar, na grade extracurricular da Rede Pública Municipal de Ensino, noçôes do estudo do Direito, que poderá ser aplicada a partir da Educação Infantil e do primeiro ao quinto ano do Ensino Fundamental, observando-se a carga horária mínima semanal (MARÍLIA, 2018).

Além disso, o conteúdo programático da disciplina será estipulado pela Secretaria da Educação do Munícipio de Marília/SP, de acordo com a seguinte diretriz, enfatizando as noções de Justiça e Cidadania e noções sobre a Constituição Federal de 1988. Por fim, a lei fixa que o Poder Executivo deverá regulamentar esta Lei e as despesas decorrentes da aplicação desta Lei correrão por conta das dotaçóes orçamentárias existentes, suplementadas se necessárias (MARÍLIA, 2018).

É importante assinalar que foram feitas atividades em sala de aula e outros ambientes, como visitas à Polícia Militar, Bosque Municipal, Corpo de Bombeiros, Unidades de Saúde, Teatro, entre outros, destacando a realizaçáo da leitura de textos informativos, documentos, histórias infantis e em quadrinhos, filmes e o estudo da Declaração Universal dos Direitos Humanos e da Constituição Federal de 1988. Dessa forma, foi sugerida a produçáo de desenho livre contendo temas ou histórias propostas, além de músicas e coreografias.

Em sintonia com isso, os alunos visitaram órgãos da Administração Pública Direta e Indireta, onde foram feitas entrevistas, palestras, reuniōes, fotos e vídeos, discussão dos assuntos na roda de conversa diária, teatro de fantoches partindo dos 
temas propostos. A propósito, foram realizadas atividades dos conteúdos listados nos eixos temáticos de forma interdisciplinar com o projeto, com a realização de trabalho artesanal.

Em verdade, os assuntos destacados foram abordados, primeiramente, com histórias infantis e, a partir dessa atividade, outras propostas foram encadeadas nesse âmbito, tais como o envolvimento do amor no cotidiano dos alunos, a família, a escola, o futuro e os conteúdos dos eixos temáticos da Educação Infantil. Ademais, histórias infantis que enfatizam conteúdos diários da vida de cada criança, salientando a ética e respeito, cultura, direitos das crianças, gênero e raça, identidade pessoal, idosos, aparência física, deficientes, boas atitudes, diferenças entre outros temas.

Além disso, houve a reprodução de histórias, de modo oral, por meio de desenhos, colagem, teatro, produção artesanal, músicas, escrita, cartazes, trabalho em grupo e brincadeiras que relacionaram partes da história como sequência, personagens e outros assuntos. Também, foi disposta a elaboração da escrita de boas atitudes, em que os alunos propuseram e escreveram o conteúdo, visando o bom relacionamento a ser praticado diariamente em sala.

Assim, leciona Roldan (2016, p. 70) que, deve ser sugerido o ensino de noçóes jurídicas para as crianças, pois estas estáo em contato com o mundo jurídico, no dia a dia, tem proximidade com o Estatuto da Criança e do Adolescente, o Código Defesa do Consumidor, Código de Trânsito Brasileiro, Estatuto do Idoso, a Declaraçáo Universal dos direitos da Criança, Declaração Universal dos Direitos do Homem e do Cidadão, alguns artigos da Constituição Federal, com ênfase para os direitos sociais. Nessa fase já tem condiçóes de aprofundar alguns conceitos de estudar algumas leis que eles afetam diretamente a vida.

Entretanto, analisando a diferença entre as pessoas, constatou-se ser necessário compreender que muitas atividades podem proporcionar o prazer em aprender, sendo preciso realizá-las, cujo intuito é a satisfação ao aprendizado, pois esse fato é imprescindível nessa idade. Em resumo, é preciso instruir os infantes, uma vez que atuaráo positivamente com as questóes sociais que nos envolvem, de modo que poderão exigir respeito e serem respeitados.

É importante frisar que, são realizadas, semanalmente, reuniôes com o corpo docente e a equipe gestora, nas quais eram relatadas as atividades a todos participantes, além de se ter, em muitas vezes, um feedback positivo dos pais de alunos, quando iam buscar seus filhos. Assim, notou-se entusiasmo dos discentes e satisfaçáo da equipe gestora com o trabalho executado, sendo reconhecido em toda cidade.

Por derradeiro, constatou-se que os resultados na realização deste projeto testificam a conscientização por parte das famílias e toda sociedade, cujo aprendizado das crianças, no sentido de que se deve respeitar o próximo e entender basicamente os direitos e deveres, mesmo em tenra idade, por meio do estudo da Declaração Universal dos Direitos Humanos e da Constituição Federal foi satisfatoriamente 
possível de serem inseridos na Educação Infantil e totalmente benéficos aos alunos e demais integrantes, segundo suas próprias opiniōes.

\section{CONSIDERAÇÓES FINAIS}

A Educação Infantil tem a incumbência da formação cultural e social da criança. Desse modo, pode-se afirmar que, educar em Direitos Humanos, objetivando a formação do valor-cidadáo, a partir da Educação Infantil, além de estar embasado nas atuais políticas educacionais, também se distingue por ser um direito dos infantes, e benéfico a toda coletividade.

Entretanto, ao se refletir acerca da igualdade de acesso e a qualidade educacional, torna-se fundamental o entendimento de que a efetividade do direito de todas as crianças à Educação é um imperativo ético, cujo escopo é o alfa da responsabilidade em acolher todas as crianças sem qualquer tipo de discriminaçáo.

No caso em apreço, tal fundamento compreende os Direitos Humanos, náo apenas como indicativos de direitos fundamentais a serem obedecidos, porém, como tutela da igualdade entre os futuros cidadãos, de modo a se respeitarem em suas diferenças. Nesse viés, o respeito à igualdade e a busca pelos direitos é indispensável para assegurar a equidade sem aniquilar as diferenças.

Ademais, o Estatuto da Criança e do Adolescente faz uso do princípio da igualdade, previsto na Constituição Federal, para corroborar que todas as crianças brasileiras têm os mesmos direitos "de condiçóes para o acesso e permanência na escola” (BRASIL, 1990). Nesse ínterim, afirma-se que elas devem ter o direito à educação, sem distinção, pois a igualdade é um arquétipo de inclusão social.

Assim, abstraiu-se da presente pesquisa que o fato de educar para os direitos humanos, prescinde então de uma tarefa compartilhada entre educadores, familiares e alunos, aptos a construírem mecanismos autônomos na produção de conhecimento. Nesse viés, a produção do conhecimento voltada para as questóes sociais relevantes traz como objetivo o primordial pacto com a liberdade do pensamento, pois é um importante vetor de integração às práticas educativas que devem ser efetivadas em diversos ambientes. Portanto, demonstrou-se a possibilidade da inclusão jurídica básica na Educação Infantil.

A consciência do pequeno cidadão se mostra como um mecanismo que auxilia na construção de valores e de sujeitos sociais mais críticos no futuro e, certamente mais atuantes na sociedade, conscientizados de que poderáo mudar a cidade, ou até o país, e serem protagonistas de sua própria história. Assim, saberes alicerçados devido a contextualização e consciência das problemáticas sociais, baseados em relaçóes horizontais de ensino-aprendizagem, mediante as quais o professor e aluno se formam e se transformam, se criam e se recriam, admitindo a autonomia ao pensamento de ambos.

Além desse fator, a construção de saberes decorrentes das atividades que envolvem a prática de inclusão do ensino jurídico, com vistas à realidade histórica, social e cultural, auxilia de modo que os educadores e educandos libertem-se de 
seus próprios pré-conceitos, pré-noçóes e jugos antecipados, pois é na relação que o sujeito contrai com os valores culturais e a sociedade, que se define que a ação educativa se torna eficaz.

Por tais razóes, as atividades que envolvem os conhecimentos básicos jurídicos podem ser introduzidas na Educação Infantil, pois os resultados com o relato de caso dado como exemplo foram satisfatórios, cujo respaldo se encontrou nos depoimentos dos alunos, demais docentes que presenciaram, famílias e equipe gestora, uma vez que, mediante práticas educativas dialógicas trouxe consigo a possibilidade dos educadores e educandos construírem processos de emancipaçáo humana que repercutem em suas maneiras de comportamento e pensamento frente à sociedade, contribuindo com a formaçáo da cidadania desses alunos.

Em suma, a presente pesquisa destacou a Educaçáo Infantil e a importância da inclusão básica do Ensino Jurídico e salientou esse elo com os Direitos Humanos, já que, pode-se aduzir que a garantia do direito à Educação, enquanto direito humano fundamental, traça um caminho fincado por inúmeros atores sociais, de modo a democratizar o ensino do Direito, levando o conhecimento desde a pré-escola.

Dessa maneira, destacou, ainda, que a proposta da inclusão jurídica na Educação Infantil se encontra alicerçada à Lei Ordinária no 8340, de 10 de dezembro de 2018, do município de Marília/SP que tem por escopo incluir, basicamente, as noçóes jurídicas, e tais questóes, nesse sentido, são de suma relevância e a implantaçáo de projetos ou oficinas pode contribuir com o exercício da cidadania. Portanto, frisa, por relevante, que na prática das atividades, o (a) docente da Educação Infantil, ou seja, pedagogo, poderá facilmente desenvolver os assuntos, uma vez que se trata da inserção básica jurídica, ou seja, não a necessidade de qualquer aprofundamento jurídico do (a) educador (a).

Assim, o Parecer CNE/CP no 5/2005 que dispõe acerca das Diretrizes Curriculares Nacionais para o Curso de Pedagogia determina que a estrutura, respeitadas a diversidade nacional e a autonomia pedagógica das instituiçóes, constituir-se-á de "estudo das relaçóes entre educaçáo e trabalho, diversidade cultural, cidadania, sustentabilidade, entre outras problemáticas centrais da sociedade contemporânea" (BRASIL, 2005, p. 24). O curso de Pedagogia demanda que os docentes sejam, também, formados para "garantir a educação, com vistas à inclusão plena, dos segmentos historicamente excluídos dos direitos sociais, culturais, econômicos, políticos" (BRASIL, 2005, p. 05).

Dessa maneira, pode-se abstrair do exposto a possibilidade, baseada na citada lei municipal, a importância em destacar tais questóes com as crianças. Assim, educar para os Direitos Humanos é, antes de tudo, assumir a postura de dialogia que mobiliza um conjunto de relações interligadas e formadas a partir de um ambiente escolar que auxilie na definiçáo das situaçôes sociais, tendo como elemento mediador seus próprios saberes, aliados à conexão com os ideais de democracia, cidadania, paz e justiça social em benefício dos alunos, da educação e do Brasil. 


\section{REFERÊNCIAS}

BENEVIDES, Maria Victoria. Educação em direitos humanos: de que se trata. Formaçáo de educadores: desafios e perspectivas. Sáo Paulo: Editora UNESP, p. 309-318, 2003.

BRASIL. (Constituição de 1988). Constituição da República Federativa do Brasil. Brasília: Senado Federal, 1988.

BRASIL. Lei no 8.069, de 13 de julho de 1990. Institui o Estatuto da Criança e do Adolescente e dá outras providências. Disponível em: <http://www.planalto.gov.br/ ccivil_03/Leis/L8069.htm>. Acesso em: 10 ago 2019.

BRASIL. Lei n. o 9.394, de 20 de dezembro de 1996. Estabelece as Diretrizes e Bases da Educação Nacional. Disponível em: http://www.mec.gov.br/seb/pdf/LDB.pdf. Acesso em 05 abr. 2019.

BRASIL. Parecer CNE/CP no 5/2005, aprovado em 13 de dezembro de 2005.

Diretrizes Curriculares Nacionais para o Curso de Pedagogia. 2005. Disponível em http:// portal.mec.gov.br/cne/arquivos/pdf/pcp05_05.pdf Acesso em 03 mar. 2020.

BRASIL. Plano nacional de educação em direitos humanos. Brasília: Secretaria Especial dos Direitos Humanos, Ministério da Educação, 2003.

BRASIL. Ministério da Educação. Conselho Nacional de Educaçáo. Resoluçáo CNE/ CP n⿳1, de 15 de maio de 2006. Institui Diretrizes Curriculares Nacionais para o Curso de Graduação em Pedagogia, licenciatura. Brasília: CNE, 2006. Disponível em: http:// portal.mec.gov.br/cne/arquivos/pdf/rcp01_06.pdf. Acesso em 05 abr. 2019.

BUENO, Silveira. Dicionário global escolar Silveira Bueno da língua portuguesa. Global Editora e Distribuidora Ltda, 2017.

CHAUÍ, Marilena. Direitos humanos e medo. In: FESTER, A. C. R. (org.) Direitos humanos e. São Paulo: Brasiliense, 1989.

CURY, Carlos Roberto Jamil. Direito à educação: direito à igualdade, direito à diferença. Cadernos de Pesquisa, n.116, p.245-262, jun. 2002.

DECLARAÇÃO E PROGRAMA DE AÇÃO DA CONFERÊNCIA MUNDIAL SOBRE OS DIREITOS HUMANOS. Viena, 1993. Disponível em http://www. oas.org/dil/port/1993\%20Declara\%C3\%A7\%C3\%A3o\%20e\%20Programa\%20 de\%20Ac\%C3\%A7\%C3\%A3o\%20adoptado\%20pela\%20Confer\%C3\%AAncia\%20 Mundial\%20de\%20Viena\%20sobre\%20Direitos\%20Humanos\%20em\%20junho\%20 de\%201993.pdf. Acesso em 04 jan. 2020.

FACCI, Marilda Gonçalves Dias. A periodização do desenvolvimento psicológico individual na perspectiva de Leontiev, Elkonin e Vigotski. Cadernos Cedes, v. 24, n. 62, p. 64-81, 2004. 
FISCHER, Leonardo. Ideias de civismo, educação e cidadania. 2018. Disponível em https://jus.com.br/artigos/64277/ideias-de-civismo-educacao-e-cidadania. Acesso em 10 mar. 2020.

FREIRE, Paulo. Ação cultural para a liberdade e outros escritos. Rio de Janeiro: Paz e Terra, 2003.

KRAMER, Sonia. De que professor precisamos para a educaçáo infantil? Uma pergunta, várias respostas. Pátio Educação Infantil. Ano 1, no 2. Ago/Nov 2003.

KRAMER, Sonia. As crianças de 0 a 6 anos nas políticas educacionais no Brasil: educação infantil e/é fundamental. Educaçáo e Sociedade, v. 27, n. 96, p. 797-818, 2006.

LEONARDO, Francisco Antonio Morilhe. Introdução do Ensino do Direito no currículo de Sociologia, no Ensino Médio, da Escola Pública. Revista Jurídica Luso Brasileira, ano, v. 1, p. 661-681, 2015.

LEONARDO, Francisco Antonio Morilhe. A inclusão de noções de Direito no currículo escolar da Rede Municipal. Revista de Estudios para el Desarrollo Social de la Comunicación, n. 13, 2016.

MARÍLIA. Câmara Municipal de Marília/SP. Lei Ordinária no 8340 de 10 de dezembro de 2018. 2018. Disponível em https://sagl.marilia.sp.leg.br/consultas/norma_juridica/ norma_juridica_mostrar_proc?cod_norma=38484. Acesso em 03 mar. 2020.

NUNES, Maria Fernanda Rezende; CORSINO, Patrícia; DIDONET, Vital. Educaçáo infantil no Brasil. Brasília: UNESCO, Ministério da Educação/Secretaria de Educação Básica, Fundação Orsa, 2011.

OLIVEIRA, Míria Gomes de; SILVA, Paulo Vinícius Baptista da. Educação Étnico-Racial e Formação Inicial de Professores: a recepção da Lei 10.639/03. Educaçáo \& Realidade, v. 42, n. 1, p. 183-196, 2017.

ORIANI, Valéria Pall. Direitos humanos na educação infantil: algumas reflexóes. Revista de Iniciação Científica da FFC, v. 8, n. 2, 2008.

PÔRTO, Inês da Fonseca. Ensino jurídico, diálogos com a imaginação: construção do projeto didático no ensino jurídico. Porto Alegre: S. Fabris, 2000.

ROLDAN, Rosilma Menezes. Como Ensinar Direito para Crianças e Jovens. Desafios, estratégias, reflexóes e experiências. São Paulo. $1^{\circ}$ Ed. 146 p. Ed. Clube dos Autores. 2016.

SAVIANI, Dermeval. A nova lei da educação: trajetória, limites e perspectivas. Campinas: Autores Associados, 1997.

VENTURINI, Gabriela. Pensamento e infância: práticas da educação infantil em tempos de interesse. 2019.

VICENTINI, Dayanne; BARROS, Marta Silene Ferreira. A humanização da criança na educação infantil: implicações da teoria histórico-cultural. Educação, v. 42, n. 1, p. 163$176,2017$. 